\title{
PENENTUAN RELIABILITAS DARI SISTEM BERDISTRIBUSI WEIBULL DENGAN METODE BAYES
}

\author{
ZAHRATUL AINI, FERRA YANUAR, IZZATI RAHMI HG \\ Program Studi S1 Matematika, \\ Fakultas Matematika dan Ilmu Pengetahuan Alam, Universitas Andalas, \\ Kampus UNAND Limau Manis Padang, Indonesia. \\ email : zahratulaini35@gmail.com
}

Diterima 9 Maret 2019 Direvisi 7 April 2019 Dipublikasikan 7 Mei 2019

\begin{abstract}
Abstrak. Nilai reliabilitas suatu sistem yang bersifat repairable dapat diduga dengan metode Bayes. Nilai reliabilitas merupakan parameter yang dianggap sebagai peubah acak yang berdistribusi Weibull. Dugaan nilai reliabilitas dirumuskan dengan $R(x)^{*}=\left(\sum_{i=1}^{n} x_{i}{ }^{\beta}\right)^{n} /\left(\sum_{i=1}^{n} x_{i}{ }^{\beta}+x^{\beta}\right)^{n}$. Untuk memperoleh nilai dugaan reliabilitas tersebut dibutuhkan nilai duga $\beta$. Pendugaan nilai $\beta$ ini diperoleh dengan metode Bayes yang menggunakan prior noninformatif. Nilai dugaan reliabilitas tersebut kemudian diaplikasikan pada sistem kerusakan mesin phosphoric acid mixer. Pada data kasus ini diperoleh nilai dugaan reliabilitas sebesar 0.732. Hal ini menginformasikan bahwa sistem tersebut masih beroperasi dengan baik, karena nilai dugaan reliabilitas sistemnya lebih besar dari 0.6.
\end{abstract}

Kata Kunci: Distribusi Weibull, Metode Bayes, Reliabilitas

\section{Pendahuluan}

Suatu mesin agar peformanya terjaga dan dapat menghasilkan produk sesuai dengan yang diinginkan harus menjalani pemeliharaan atau perawatan sistem. Menurut Supandi (1990) perawatan adalah suatu konsepsi dari semua aktivitas yang diperlukan untuk menjaga atau mempertahankan kualitas peralatan agar tetap berfungsi dengan baik seperti dalam kondisi sebelumnya. Dalam menentukan waktu yang tepat untuk melakukan perawatan dilakukan uji kehandalan. Uji kehandalan dapat dihitung melalui reliabilitas. Reliabilitas menyatakan seberapa besar kemungkinan suatu sistem dapat berfungsi dengan baik pada waktu $x$. Reliabilitas suatu sistem dapat dihitung berdasarkan data waktu antar kerusakan yang disajikan oleh sistem tersebut. Menurut Modarres dan Kaminskiy [5], pada sistem yang bersifat repairable atau sistem dapat diperbaiki, nilai reliabilitas dapat diduga dengan menggunakan metode Klasik dan metode Bayes.

Pada tugas akhir ini nilai reliabilitas diduga dengan menggunakan metode Bayes. Metode Bayes menggabungkan fungsi likelihood dan distribusi prior sehingga diperoleh distribusi posterior. Nilai harapan dari distribusi posterior disebut dengan nilai dugaan Bayes. Pada tugas akhir ini akan dibahas mengenai pendugaan nilai reliabilitas suatu sistem jika sistem tersebut berdistribusi Weibull dua 
parameter. Distribusi Weibull merupakan salah satu distribusi data statistik yang paling banyak digunakan untuk data waktu kerusakan dalam analisis kehandalan dan dapat menyajikan keakuratan kegagalan dengan sampel yang kecil. Pendugaan nilai reliabilitas tersebut memerlukan nilai duga parameter Weibull, sehingga dilakukan pendugaan parameter berdistribusi Weibull dengan menggunakan metode Bayes. Pada tugas akhir ini juga akan menghitung nilai dugaan reliabilitas untuk data kerusakan mesin phosphoric acid mixer.

\section{Landasan Teori}

\subsection{Nilai Harapan}

Definisi 2.1. [1] Jika $X$ menyatakan suatu peubah acak kontinu dengan fungsi kepekatan peluang $f(x)$ maka nilai harapan dinyatakan sebagai berikut

$$
E(X)=\int_{-\infty}^{\infty} x f(x) d x .
$$

Hasil integral harus konvergen, jika tidak maka bermakna $E(X)$ tidak ada.

\subsection{Distribusi Peubah Acak Kontinu}

\section{Distribusi Weibull}

Definisi 2.2. [6] Sebuah peubah acak kontinu $X$ dikatakan berdistribusi Weibull dengan parameter $\beta>0$ dan $\theta>0$ jika memiliki fungsi kepekatan peluang

$$
f(x)=\frac{\beta}{\theta} x^{\beta-1} e^{-\left(\frac{x^{\beta}}{\theta}\right)} \text {, untuk } x>0, \text { dan } 0 \text { selainnya. }
$$

Fungsi kepekatan peluang kumulatif $X$ yaitu

$$
F(x)=1-e^{-\left(\frac{x^{\beta}}{\theta}\right)} .
$$

\section{Distribusi Uniform}

Distribusi Uniform pada selang $(a, b)$ memiliki fungsi kepekatan peluang [1]:

$$
f(x)=\frac{1}{(b-a)} \text { untuk } a<x<b \text { dan } 0 \text { selainnya. }
$$

\section{Distribusi Eksponensial}

Definisi 2.3. [9] Sebuah peubah acak kontinu $X$ dikatakan berdistribusi Eksponensial dengan parameter $\theta>0$ jika memiliki fungsi kepekatan peluang

$$
f(x)=\frac{1}{\theta} e^{-\left(\frac{x}{\theta}\right)} \text { dan } 0 \text { selainnya. }
$$

Fungsi kepekatan peluang kumulatif $X$ yaitu

$$
F(x)=1-e^{-\left(\frac{x}{\theta}\right)} .
$$




\subsection{Metode Bayes}

Pada metode Bayes, parameter yang ingin diduga dianggap sebagai peubah acak. Metode Bayes menggabungkan fungsi likelihood dan distribusi prior sehingga diperoleh distribusi posterior. Nilai harapan dari distribusi posterior disebut nilai dugaan Bayes.

\section{Fungsi Likelihood}

Definisi 2.4. [1] Fungsi kepekatan peluang bersama peubah acak $X_{1}, X_{2}, \cdots, X_{n}$ yang dihitung pada $x_{1}, x_{2}, \cdots, x_{n}$, adalah $f\left(x_{1}, x_{2}, \cdots, x_{n} \mid \theta\right)$ disebut sebagai fungsi likelihood. Untuk $x_{1}, x_{2}, \cdots, x_{n}$ tetap, fungsi likelihood adalah fungsi dari parameter $\theta$ yang dinotasikan dengan $f(\mathbf{x} \mid \theta)$. Jika $X_{1}, X_{2}, \cdots, X_{n}$ merupakan sampel acak dari $f(x ; \theta)$ maka

$$
\begin{aligned}
f(\mathbf{x} \mid \theta) & =f\left(x_{1} ; \theta\right) f\left(x_{2} ; \theta\right) \cdots f\left(x_{n} ; \theta\right) \\
& =\prod_{i=1}^{n} f\left(x_{i} ; \theta\right) .
\end{aligned}
$$

\section{Distribusi Prior}

Distribusi prior adalah distribusi awal yang memberikan informasi tentang parameter yang tidak diketahui nilainya. Jenis-jenis distribusi prior:

(1) Berdasarkan bentuk distribusi pola data. Jika distribusi prior dan distribusi posterior merupakan satu keluarga, maka disebut distribusi prior sekawan.

(2) Berdasarkan informasi mengenai distribusi pada penelitian yang telah dilakukan sebelumnya. Jika tidak terdapat informasi mengenai distribusi pada penelitian sebelmunya, maka disebut distribusi prior noninformatif. Distribusi prior noninformatif dapat diperoleh dengan metode Jeffrey.

\section{Metode Jeffrey}

Aturan Jeffrey menyatakan bahwa distribusi prior noninformatif untuk suatu parameter tunggal $\theta$ pada suatu peubah acak $X$ yaitu [2]

$$
f(\theta)=\sqrt{I(\theta)}
$$

Dengan $I(\theta)$ merupakan Informasi Fisher yang dirumuskan dengan

$$
I(\theta)=-E\left[\frac{\partial^{2} \ln f(\mathbf{x} \mid \theta)}{\partial \theta^{2}}\right] .
$$

\section{Distribusi Posterior}

Definisi 2.5. [9] Distribusi dari $\theta$ jika diberikan data $\mathbf{x}$, disebut sebagai distribusi posterior yang diperoleh dari

$$
f(\theta \mid \mathbf{x})=\frac{f(\mathbf{x} \mid \theta) f(\theta)}{f(\mathbf{x})},
$$


dengan $f(\mathbf{x})$ merupakan fungsi kepekatan peluang marginal dari $\mathbf{x}$.

Fungsi kepekatan peluang marginal dari $\mathbf{x}$ pada definisi diatas dapat dihitung dengan rumus $f(\mathbf{x})=\int_{-\infty}^{\infty} f(\mathbf{x} \mid \theta) f(\theta) d \theta$ untuk $\theta$ kontinu.

\subsection{Reliabilitas}

Reliabilitas dapat didefinisikan sebagai peluang suatu sistem akan memiliki kinerja yang sesuai dengan fungsi yang dibutuhkan dalam periode waktu tertentu [8]. Analisis reliabilitas digunakan untuk melihat tingkat kehandalan suatu sistem. Jika peubah acak $X$ menyatakan waktu kegagalan sebuah sistem, maka reliabilitas dari sistem pada waktu $x$ didefinisikan sebagai berikut [1]

$$
R(x)=P[X>x]=1-F_{X}(x) .
$$

Reliabilitas dapat dikategorikan menjadi dua yaitu repairable (sistem dapat diperbaiki) dan nonrepairable. Nilai reliabilitas dari sistem yang bersifat repairable dapat diduga dengan metode pendugaan parameter yaitu metode Bayes [5]. Pendugaan reliabilitas dengan metode Bayes pada distribusi tertentu dengan parameter $\theta$ dinotasikan dengan $R(x)^{*}$ dan didefinisikan sebagai [7]:

$$
R(x)^{*}=\int_{\theta} R(x) f(\theta \mid X) d \theta
$$

\subsection{Markov Chain Monte Carlo(MCMC)}

Metode MCMC merupakan metode pendugaan parameter dengan menggunakan teknik simulasi numerik yang digunakan untuk menyelesaikan masalah pemodelan yang kompleks. Pada metode Bayes, pendugaan parameter diperoleh dengan menggunakan distribusi posterior marginal. Distribusi ini diperoleh dengan cara mengintegralkan distribusi posterior bersama dari seluruh parameter. Untuk model yang cukup kompleks, proses integrasi tersebut sangat sulit dikerjakan sehingga untuk mendapatkan distribusi posterior marginal dilakukan teknik simulasi numerik berupa MCMC [3]. Sampel yang dihasilkan harus konvergen terhadap posterior. Kekonvergenan sampel dapat diketahui dari nilai $M C$ Error, autocorrelation plot, trace plot, dan quantile plot.

\subsection{Koefisien Korelasi dan Uji Mann}

Menurut Ebeling [4] tahap awal mengidentifikasi distribusi dari suatu data dapat dilakukan dengan dua metode, yaitu dengan probability plot dan least square curve fitting. Pada metode least square curve fitting distribusi yang dipilih sebagai distribusi yang paling sesuai adalah distribusi yang mempunyai nilai koefisien korelasi terbesar. Adapun rumus koefisien korelasi adalah [4]

$$
r=\frac{n \sum_{i=1}^{n} x_{i} y_{i}-\sum_{i=1}^{n} x_{i} \sum_{i=1}^{n} y_{i}}{\sqrt{\left(n \sum_{i=1}^{n} x_{i}^{2}-\left(\sum_{i=1}^{n} x_{i}\right)^{2}\right)\left(n \sum_{i=1}^{n} y_{i}^{2}-\left(\sum_{i=1}^{n} y_{i}\right)^{2}\right)}} .
$$


Perhitungan umum untuk metode least square curve fitting yaitu:

$$
F\left(t_{i}\right)=\frac{i-0.3}{n+0.4} ; 0<i<n .
$$

Setiap distribusi memiliki definisi $x_{i}$ dan $y_{i}$ berbeda. Berikut ini merupakan definisi $x_{i}$ dan $y_{i}$ sesuai dengan distribusi yang diuji

(1) Distribusi Weibull:

$$
x_{i}=\ln t_{i}, y_{i}=\ln \left(\ln \frac{1}{1-F\left(t_{i}\right)}\right) .
$$

(2) Distribusi Normal:

$$
x_{i}=t_{i}, y_{i}=\phi^{-1}\left[F\left(t_{i}\right)\right] .
$$

(3) Distribusi Lognormal:

$$
x_{i}=\ln t_{i}, y_{i}=\phi^{-1}\left[F\left(t_{i}\right)\right] \text {, }
$$

di mana $t_{i}$ merupakan lama waktu ke- $i$ yang dilalui sampai suatu sistem gagal berfungsi dan $n$ merupakan banyaknya data kegagalan. Setelah dipilih distribusi yang sesuai, selanjutnya menguji kecocokan distribusi tersebut. Untuk mengetahui apakah suatu data berdistribusi Weibull dilakukan uji Mann. Hipotesis uji ini yaitu

$$
\begin{aligned}
& H_{0} \text { : Data waktu kegagalan berdistribusi Weibull, } \\
& H_{1} \text { : Data waktu kegagalan tidak berdistribusi Weibull, }
\end{aligned}
$$

dengan statistik uji yaitu

$$
M=\frac{k_{1} \sum_{i=k_{1}}^{n-1}\left(\frac{\ln t_{i+1}-\ln t_{i}}{M_{i}}\right)}{k_{2} \sum_{i=1}^{k_{2}}\left(\frac{\ln t_{i+1}-\ln t_{i}}{M_{i}}\right)},
$$

di mana $k_{1}=\left\lfloor\frac{n}{2}\right\rfloor, k_{2}=\left\lfloor\frac{n-1}{2}\right\rfloor, M_{i}=Z_{i+1}-Z_{i}$, dan $Z_{i}=\ln \left[-\ln \left(1-\frac{i-0.5}{n+0.25}\right)\right]$.

Jika $M>F_{\text {tabel }}=F_{\alpha, 2 k_{1}, 2 k_{2}}$ maka tolak nilai $H_{0}$. Nilai $F_{\text {tabel }}$ dapat ditentukan dari tabel distribusi $F$ dengan jumlah derajat bebas penyebut $2 k_{1}$ dan jumlah derajat bebas pembilang $2 k_{2}[4]$.

\section{Pembahasan}

\subsection{Pendugaan Nilai Reliabilitas}

Nilai reliabilitas suatu peubah acak $X$ berdistribusi Weibull dua parameter yaitu

$$
\begin{aligned}
R(x) & =1-F_{X}(x) \\
& =1-\left(1-e^{-\left(\frac{x^{\beta}}{\theta}\right)}\right) \\
& =e^{-\left(\frac{x^{\beta}}{\theta}\right)}
\end{aligned}
$$

Nilai reliabilitas dari suatu sistem yang bersifat reliable diperoleh dengan mencari nilai dugaan reliabilitas sesuai persamaan (2.6). Dalam hal ini diperlukan distribusi posterior. Distribusi posterior diperoleh dari fungsi likelihood dan distribusi prior. 


\section{Fungsi Likelihood}

Jika diketahui $X_{1}, X_{2}, \cdots, X_{n}$ adalah peubah acak berdistribusi Weibull dua parameter, $\theta$ dan $\beta$ atau ditulis $X_{i} \sim W E I(\theta, \beta)$, maka berdasarkan Definisi 2.4 dan Definisi 2.5, fungsi likelihoodnya yaitu

$$
\begin{aligned}
f(\mathbf{x} \mid \theta) & =\frac{\beta}{\theta} x_{1}^{\beta-1} e^{-\left(\frac{x_{1} \beta}{\theta}\right)} \cdots \frac{\beta}{\theta} x_{n}^{\beta-1} e^{-\left(\frac{x_{n} \beta}{\theta}\right)} \\
& =\left(\frac{\beta}{\theta}\right)^{n} \prod_{i=1}^{n} x_{i}^{\beta-1} e^{-\left(\sum_{i=1}^{n} x_{i}{ }^{\beta} / \theta\right)} .
\end{aligned}
$$

\section{Prior Noninformatif}

Suatu peubah acak $X_{1}, X_{2}, \cdots, X_{n}$ berdistribusi Weibull dua parameter. Misalkan $\mathbf{v}=(\theta, \beta)$ suatu peubah acak. Asumsikan $\theta$ dan $\beta$ saling bebas, distribusi prior $f(\mathbf{v})=f(\theta) f(\beta)$. Misal $f(\theta)$ merupakan distribusi prior noninformatif dari parameter $\theta$ dan $f(\beta)$ merupakan distribusi prior noninformatif dari parameter $\beta$. Distribusi prior noninformatif $f(\theta)$ diperoleh dengan menggunakan metode Jeffrey. Berdasarkan aturan Jeffrey, persamaan (2.4) dan persamaan (3.2) diperoleh

$$
\begin{aligned}
I(\theta) & =-E\left[\frac{n}{\theta^{2}}+\frac{2 \sum_{i=1}^{n} x_{i}{ }^{\beta}}{\theta^{3}}\right] \\
& =\frac{n}{\theta^{2}}
\end{aligned}
$$

sehingga diperoleh

$$
f(\theta)=\frac{\sqrt{(n)}}{\theta}
$$

Distribusi prior noninformatif yang dipilih untuk $\beta$ adalah distribusi Uniform. Distribusi prior untuk $\beta$ dengan $0<\beta<b$ yaitu $\frac{1}{b}$. Misal $b=1$, sehingga $f(\beta)=1$ dan diperoleh distribusi prior untuk $\mathbf{v}$ yaitu

$$
f(\mathbf{v})=\frac{\sqrt{n}}{\theta} .
$$

\section{Distribusi Posterior}

Berdasarkan Definisi 2.5, persamaan (3.2) dan persamaan (3.3) diperoleh distribusi posterior:

$$
\begin{aligned}
f(\mathbf{v} \mid \mathbf{x}) & =\frac{\left(\frac{\sqrt{n} \beta^{n}}{\theta^{n+1}}\right) \prod_{i=1}^{n} x_{i}^{\beta-1} e^{-\left(\sum_{i=1}^{n} x_{i}{ }^{\beta} / \theta\right)}}{\int_{0}^{\infty} \int_{0}^{\infty}\left(\frac{\sqrt{n} \beta^{n}}{\theta^{n+1}}\right) \prod_{i=1}^{n} x_{i}^{\beta-1} e^{-\left(\sum_{i=1}^{n} x_{i} \beta / \theta\right)} d \theta d \beta} \\
& =K^{-1} \frac{\beta^{n}}{\theta^{n+1}} e^{-(h / \theta)} m^{\beta-1}
\end{aligned}
$$

dengan $h=\sum_{i=1}^{n} x_{i}{ }^{\beta}$ dan $m=\prod_{i=1}^{n} x_{i}$ dimana $K=\int_{0}^{\infty} \frac{\beta^{n} m^{\beta-1}}{h^{n}} \Gamma(n) d \beta$ sehingga distribusi posteriornya yaitu

$$
f(\mathbf{v} \mid \mathbf{x})=\frac{\frac{\beta^{n}}{\theta^{n+1}} e^{-(h / \theta)} m^{\beta-1}}{\Gamma(n) \int_{0}^{\infty} \frac{\beta^{n} m^{\beta-1}}{h^{n}} d \beta}
$$


Distribusi posterior yang ditunjukkan pada persamaan (3.4) akan digunakan untuk menghitung nilai dugaan reliabilitas. Tetapi tidak mudah untuk menemukan distribusi posterior secara langsung. Oleh karena itu dilakukan transformasi data.

Misal suatu peubah acak $Y$ dengan $y=x^{\beta}$ sehingga $x=y^{1 / \beta}$. Hasil transformasi menunjukkan bahwa $Y$ merupakan peubah acak berdistribusi Eksponensial.

$$
\begin{aligned}
f(\mathbf{y} \mid \theta) & =\frac{1}{\theta^{n}} e^{-\left(\frac{\sum_{i=1}^{n} y_{i}}{\theta}\right)}, \\
f(\theta) & =\sqrt{\frac{n}{\theta^{2}}} .
\end{aligned}
$$

Berdasarkan persamaan (3.5) dan persamaan (3.6) diperoleh distribusi posterior berikut

$$
f(\theta \mid \mathbf{y})=\frac{\left(\sum_{i=1}^{n} y_{i}\right)^{n} e^{-\sum_{i=1}^{n} y_{i} / \theta}}{\Gamma(n) \theta^{n+1}} .
$$

Nilai reliabilitas peubah acak $Y$ berdasarkan persamaan (2.3) dan persamaan (2.5) yaitu

$$
R(y)=e^{-(y / \theta)} .
$$

Nilai duga reliabilitas peubah acak $Y$ berdasarkan persamaan (2.6), persamaan (3.7) dan persamaan (3.8), yaitu

$$
\begin{aligned}
R(y)^{*} & =\int_{0}^{\infty} e^{-(y / \theta)} \frac{\left(\sum_{i=1}^{n} y_{i}\right)^{n} e^{-\sum_{i=1}^{n} y_{i} / \theta}}{\Gamma(n) \theta^{n+1}} d \theta \\
& =\frac{\left(\sum_{i=1}^{n} y_{i}\right)^{n}}{\left(\sum_{i=1}^{n} y_{i}+y\right)^{n}} .
\end{aligned}
$$

karena $y=x^{\beta}$ diperoleh nilai dugaan reliabilitas peubah acak $X$ yaitu

$$
R(x)^{*}=\frac{\left(\sum_{i=1}^{n} x_{i}^{\beta}\right)^{n}}{\left(\sum_{i=1}^{n} x_{i}^{\beta}+x\right)^{n}} .
$$

\section{Nilai Duga $\beta$}

Distribusi posterior marginal bagi $\beta$

$$
\begin{aligned}
& f(\beta \mid \mathbf{x})=\int_{0}^{\infty} \frac{\beta^{n} e^{-\left(\sum_{i=1}^{n} x_{i}{ }^{\beta} / \theta\right)} \prod_{i=1}^{n} x_{i}^{\beta-1}}{\theta^{n+1} \Gamma(n) \int_{0}^{\infty} \frac{\beta^{n} \prod_{i=1}^{n} x_{i}{ }^{\beta-1}}{\left(\sum_{i=1}^{n} x_{i}\right)^{n}} d \beta} d \theta \\
& =\frac{\beta^{n} \prod_{i=1}^{n} x_{i}^{\beta-1}}{\left(\sum_{i=1}^{n} x_{i}^{\beta}\right)^{n} \int_{0}^{\infty} \frac{\beta^{n} \prod_{i=1}^{n} x_{i}^{\beta-1}}{\left(\sum_{i=1}^{n} x_{i}\right)^{n}} d \beta} .
\end{aligned}
$$

sehingga nilai duga bagi parameter $\beta$ :

$$
E(\beta \mid X)=\int_{0}^{\infty} \frac{\beta^{n} \prod_{i=1}^{n} x_{i}^{\beta-1}}{\left(\sum_{i=1}^{n} x_{i}{ }^{\beta}\right)^{n} \int_{0}^{\infty} \frac{\beta^{n} \prod_{i=1}^{n} x_{i}^{\beta-1}}{\left(\sum_{i=1}^{n} x_{i}\right)^{n}} d \beta} d \beta
$$


Pendugaan parameter $\beta$ yang ditunjukkan pada persamaan (3.11) tidak bisa ditentukan secara eksak, maka digunakan metode MCMC untuk pendugaannya.

\subsection{Nilai duga Reliabilitas pada Data Kerusakan Mesin Phosporic Acid Mixer}

\section{Identifikasi Distribusi}

Pengidentifikasian distribusi yang sesuai pada data kerusakan mesin Phosporic Acid Mixer dilakukan dengan metode least square curve fitting dan Uji Mann.

(1) Least Square Curve Fitting.

Distribusi yang memiliki nilai koefisien korelasi tertinggi merupakan distribusi yang paling sesuai dengan data.

Tabel 1. Nilai Koefien Korelasi Data Kerusakan Mesin Phosporic Acid Mixer

\begin{tabular}{|c|c|}
\hline Distribusi & Koefisien Korelasi $(r)$ \\
\hline Weibull & 0.975 \\
\hline Lognormal & 0.969 \\
\hline Normal & 0.853 \\
\hline
\end{tabular}

Dari Tabel 1 diketahui bahwa nilai koefisien korelasi tertinggi yang dihasilkan oleh distribusi Weibull.

(2) Uji Mann.

Hipotesis :

$H_{0}$ : Data $t_{i}$ kerusakan mesin phosporic acid mixer berdistribusi Weibull,

$H_{1}$ : Data $t_{i}$ kerusakan mesin phosporic acid mixer tidak berdistribusi Weibull, dengan $\alpha=0.05$.

Uji Statistik :

$$
\begin{aligned}
M & =\frac{11(0.748633+0+\cdots+1.68002)}{10(0.162502+\cdots+0.53759)} \\
& =1.528
\end{aligned}
$$

Diperoleh $F_{\text {tabel }}=F_{0.05,22,20}=2.07$ dan $M<F_{\text {tabel }}=1.528<2.07$. Artinya data kerusakan mesin phosporic acid mixer berdistribusi Weibull.

\section{Nilai Dugaan Reliabilitas}

Parameter $\beta$ akan diduga dengan metode MCMC dengan algoritma Gibbs Sampler.

Berdasarkan $M C$ Error yang ditunjukkan pada Tabel 2 dapat disimpulkan bahwa data sampel bangkitan yang dihasilkan konvergen terhadap posterior.

Nilai dugaan reliabilitas untuk data kerusakan mesin phosporic acid mixer berdasarkan persamaan (3.9) yaitu

$$
R(t)^{*}=\frac{\left(\sum_{i=1}^{22} t_{i}^{0.9243}\right)^{22}}{\left(\sum_{i=1}^{22} x_{i}^{0.9243}+t\right)^{22}}
$$


Tabel 2. Hasil Uji Statistik Parameter $\beta$ menggunakan aplikasi Winbugs Mixer

\begin{tabular}{|c|c|c|c|c|}
\hline Parameter & Mean & Standar Deviasi & $5 \%$ Error & MC Error \\
\hline$\beta$ & 0.9243 & 0.05874 & $29.37 \times 10^{-4}$ & $6.359 x 10^{-4}$ \\
\hline
\end{tabular}

jika $t=14$, maka

$$
\begin{aligned}
R(14)^{*} & =\frac{\left(5^{0.9243}+6^{0.9243}+\cdots+132^{0.9243}+214^{0.9243}\right)^{22}}{\left(5^{0.9243}+6^{0.9243}+\cdots+132^{0.9243}+214^{0.9243}+14^{0.9243}\right)^{22}} \\
& =\frac{804.047^{22}}{(804.047+11.465)^{22}} \\
& =0.732 .
\end{aligned}
$$

Suatu reliabilitas dikatakan baik jika nilai reliabilitasnya semakin mendekati 1 . Anggap bahwa jika nilai relibilitas besar dari 0.6 maka sistem diduga masih berfungsi dengan baik pada waktu $t$. Nilai dugaan reliabilitas mesin phosporic acid mixer yang dihasilkan sebesar 0.732. Oleh karena itu sistem tersebut bernilai baik.

\section{Kesimpulan}

Nilai dugaan reliablitas sistem yang berdistribusi Weibull dua parameter dengan metode Bayes yaitu $R(x)^{*}=\frac{\left(\sum_{i=1}^{n} x_{i}^{\beta}\right)^{n}}{\left(\sum_{i=1}^{n} x_{i}^{\beta}+x\right)^{n}}$. Nilai dugaan reliabilitas tersebut diterapkan pada data kerusakan mesin phosporic acid mixer dan dapat disimpulkan bahwa reliabilitas sistem tersebut bernilai baik.

\section{Daftar Pustaka}

[1] Bain, L.J., Engelhardt, M., 1992, Introduction to Probability and Mathematical Statistic, Edisi ke-2, Duxbury Press, California

[2] Berger, J.O., 1993, Statistical Decision Theory and Bayesian Analysis, Edisi ke-2, Springer-Verlag, New York

[3] Carlin, B.P., Chib, S., 1995, Bayesian model choice via Markov Chain Monte Carlo methods, Journal of the Royal Statistical Society, Ser. B. 57(3) : $473-$ 484

[4] Ebeling, C. E., 1997, An Introduction to Reliability and Maintainability Engineering, The McGraw-Hill, Singapore

[5] Modarres, M., Kaminskiy, M., 2009, Reliability Engineering and Risk Analysis, Marcel Dekker, New York

[6] Ntzoufras, I., 2009, Bayesian Modeling Using Winbugs,John Wiley and Sons, New Jersey

[7] Savchuk, V.P., Tsokos, C.P., 2011, Bayesian Theory and Methods with Applications, Atlantis Press, Amsterdam

[8] Sinha, S.K., Kale, B.K., 1980, Life Testing and Reliability Estimation, Wiley Eastern Limited, Virginia

[9] Walpole, R.E., dan Myers, R.H., 1995, Ilmu Peluang dan Statistika untuk Insinyur dan Ilmuwan, Edisi ke-4, ITB, Bandung 